\title{
The most preferable method for distal hypospadias surgery: TIPU Technique
}

\author{
Mehmet Şerif Arslan*a, Ersin Köksal ${ }^{b}$, Turan Yıldız ${ }^{\mathrm{d}}$, Leyla Tekşan Özalp ${ }^{\mathrm{c}}$, Cengiz Kaya ${ }^{\mathrm{e}}$ \\ ${ }^{a}$ Department of Pediatric Surgery, Obstetrics\& Gynecology and Children's Hospital, Samsun, Turkey \\ ${ }^{b}$ Department of Anesthesiolgy and Reanimation, Faculty of Medicine, Ondokuz Mayls University, Samsun, Turkey \\ ${ }^{c}$ Department of Anesthesiolgy and Reanimation, Obstetrics and Gynecology and Children's Hospital, Samsun, Turkey \\ ${ }^{d}$ Department of Pediatric Surgery, Faculty of Medicine, Sakarya University, Sakarya, Turkey \\ ${ }^{e}$ Department of Anesthesiolgy and Reanimation, Faculty of Medicine, Ondokuz Mayls University, Samsun, Turkey
}

ARTICLE INFO ABSTRACT

\section{Article History \\ Received $\quad 09 / 10 / 2012$ \\ Accepted 26/12/2012}

\section{* Correspondence to:}

Mehmet Şerif Arslan

Department of Pediatric Surgery,

Obstetrics\&Gynecology and Children's

Hospital, Samsun, Turkey

e-mail:msarslan47@gmail.com

Keywords:

Complication rate

Hypospadias

TIPU

Urethroplasty
The purpose of this study is to demonstrate the efficiency of tubularized incised-plate urethroplasty (TIPU) method and the complication rates with postoperative early periodical urethral dilatations. Hypospadias is one of the most common congenital anomaly in male genital system. Retrospectively 45 case's records which had distal hypospadias and undergone surgery were studied in Samsun Obstetrics and Gynecology and Children's Hospital. The ages of the patients, their meatus locations, cordi existence, suture materials, stenting times, complication incidences after surgery, were evaluated. None of the patients had urethrocutoneous fistule, meatal stenosis, or wound place infection. In all cases, the cosmetic results satisfied both the patient's family and the doctor. TIPU is the most outstanding treatment alternative in distal hypospadias, when its advantages, such as less complication ratios, perfect cosmetic and funtional results are considered.

\section{J. Exp. Clin. Med., 2013; 30:23-25}

(C) 2013 OMU

\section{Introduction}

Hypospadias is one of the most common congenital anomaly of male genital system. Various studies in our country demonstrate that frequency of hypospadias varies between $0.39 \%$ and $0.83 \%$ (Kayıkçı et al., 2005). Hypospadias is defined as an anomaly which begins with an embryological development disorder of urethral corpus spongiosum and ventral prepicium and leads to an abnormality in penile curvature (Baskin and Ebbers, 2006). The level of hypospadias is defined as the location of incomplete closure of the penis tissue that forms the urethra and it can be found anywhere between perineum and glans (Snodgrass et al., 2007). It is classified as distal and proximal hypospadias according to the localization of urethral opening. Nearly, 70 to $80 \%$ of the cases have distal hypospadias (Hadidi and Azmy, 2004). Whereas the basic principals do not show significant variability in its treatment, different healing methods are proposed for distal hypospadias. Some of the most widely applied techniques for this abnormality in today's medicine, are Meatal Advance- ment and Glanuloplasty (MAGPI), and Mathieu, Snodgrass tubularized incised-plate urethroplasty (TIPU). The factors that affect the preference of the technique to be applied for this treatment are the location of meatus, the existance or absence of cordi, distal urethra hypoplasy, glans configuration and the surgeon's attitude towards the technique (Ebu-Arafeh et al., 1998). TIPU became very popular in recent years and it is widely used. In this study, we aimed to demonstrate the efficiency of TIPU method and the complication rates with postoperative early periodical urethral dilatations.

\section{Materials and methods}

We reviewed retrospectively 45 cases with distal hypospadias operated by using TIPU technique described below between July 2010 and June 2012 in Samsun Obstetrics and Gynecology and Children's Hospital. The ages, meatus localization, cordi existence, suture materials used in surgery, stenting times, and the complication incidences of the patients were evaluated. Complications were fistula formation, meatal 
stenosis and infection. Distal hypospadias were classified as glanular, coronal, subcoronal and mid-penile according to the localization of urethral opening. TIPU method was used as the surgical technique, which was defined by Snodgrass in 1994. De-epithelialized tissue was used to support urethroplasty in all cases except for glanular types. Penile degloving was applied successfully to 8 patients $(17.7 \%)$ with cordi. Eight french silicon catheter was used as urethral stent, and 6/0 PDS in urethroplasty. In postoperative $2^{\text {nd }}$ day wound dressings were removed. Stent removal was performed at $3^{\text {rd }}$ to $5^{\text {th }}$ days $(4 \pm 1)$. Hospitalization times varied between 4 to 6 days. At the $2^{\text {nd }}, 4^{\text {th }}, 8^{\text {th }}$ and $16^{\text {th }}$ weeks after surgery, patients were evaluated by urination calibrations, urethral calibration control with 6-8f dilatators and cosmetic result in physical examination (Fig. 1).

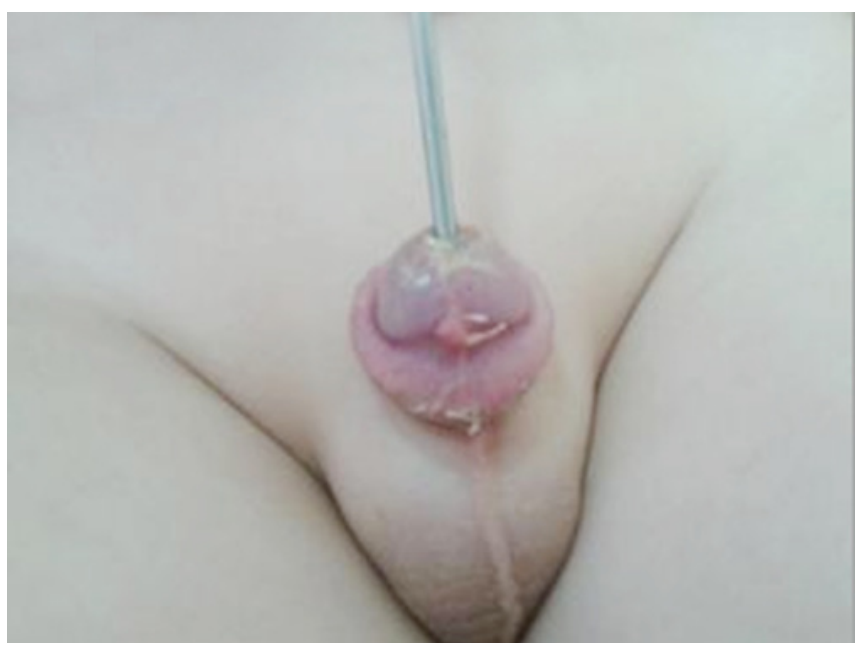

Fig. 1. View with urethral dilatator in postoperative 4th week.

\section{Results}

The avarage age of the patients was 3.2 years ( 7 months to 7 years old). Regarding their external urethral meatus localization, the results can be listed as; 5 cases $(11.1 \%)$ glanular, 14 cases $(31.1 \%)$ coronal, 21 cases $(46.6 \%)$ subcoronal and 5 cases $(11.1 \%)$ midpenile. None of the patients developed urethrocutaneous fistula, meatal stenosis, or wound infection (Table 1). The cosmetic results of all patients satisfied both the patient's family and the doctor. The patients were followed for 4 months to 2 years.

\section{Discussion}

What causes hypospadias is not exactly known. However, it can be defined as a genital pathology, in which some factors play crucial roles. Some of these factors are environmental, enzymatic, natural endocrinological causes and local tissue anomalies. Hypospadias can be a result of one of these factors or many of these factors at the same time. Although fre-

Table 1. The frequency of cordi, type of surgery and complication rates according to meatus location

\begin{tabular}{lccccc} 
& \multicolumn{3}{c}{ Meatus localization (n) } & $\begin{array}{c}\text { Complication } \\
(\mathbf{n} / \mathbf{\%})\end{array}$ \\
\hline Cordi & Glanular & Coronal & Subcoronal & Midpenil & \\
& & & 4 & 4 & \\
$\begin{array}{l}\text { Surgery } \\
(\text { TIPU) }\end{array}$ & Glanular & Coronal & Subcoronal & Midpenil & \\
& 5 & 14 & 21 & 5 & $0 / 0$ \\
\hline
\end{tabular}

quency of its occurence varies, nearly $70-80 \%$ of the cases are recorded as those which have urethral opening with distal location (Hadidi and Azmy, 2004). In treating this relatively common anomaly TIPU, MAGPI, and Mathieu techniques are most accepted ones regarding their consequences in surgical procedures (Küçükaydın et al., 1996; Baskin and Ebbers, 2006).

The goal in the hypospadias surgery is to achieve a functionally and cosmetically normal penis in just one surgical intervention. A successful treatment should bring about a vertically slit glandular meatus, a conical glans, a straight penis during erection, and a decent and firm skin (Cooper and Synder, 2000). In urethroplasty, absorbable sutures such as 6-0, 7-0 polydiaxone (PDS; Ethicon Inc., Somerville, NJ, USA), polyglactine (Vicryl; Ethicon Inc., Somerville, NJ, USA) are used. Urethral stents, used in this treatment are $6 \mathrm{~F}, 8 \mathrm{~F}$ feeding, latex and silicon catheter.

Today, appropriate surgical techniques have decreased the occurence of complications to very low levels. The optimal time for full recovery for cases with hypospadias, is accepted as 6-15 months (Söylet, 2010). We had cases with distal hypospadias, as young as 7 months old, which had undergone surgery. Snoddgrass recorded 328 cases in $1999.2 \%$ of these cases had fistula and 1\% had meastenosis (Snodgrass, 1994). Their cosmetic apperances were found satisfactory. Similarly, none of our cases developed urethral fistula or meatal stenosis.

When we search other surgical methods, in various studies Mathieu method were recorded with complication incidinces with frequencies as $0 \%$ to $18.75 \%$ (Hadidi and Azmy, 2004; Yesildag et al., 2004). In a study which compared Mathieu with TIPU, it was found that TIPU technique had a shorter operation time and a lesser complication frequency. The cases that were applied Mathieu technique, reported two patients with fistula and one patient with indemeatal stenosis. One patient among the cases with TIPU had glans widening. The cases that were applied TIPU technique have been reported to have better cosmetic results (Oswald et al., 2000).

As to MAGPI technique, it was found that it was applied more easily. However, this technique can be applied only when meatus is near to glans end, and urethral meatus is mobile (Duckett and Synder, 1992). Park et al. (1994) reported that they had 100 cases, all underwent MAGPI method. Six cases among them were reoperated due to cosmetic results and cordi adjustment. Uygur et al. (2002) reported 7.7\% of 91 MAGPI cases had meatel stenosis. We preferred TIPU method to apply to all our patients. None of them needed reoperation.

It is reported that suture material which is used in hypospadias surgery could lead fistula development (Snodgrass, 1999b). Ulman et al. (1997) found that in urethroplasty with $6 / 0$ vicyrile exact fold continued repairing had higher frequency of occurence fistula development, than in urethroplasty with 7/0 PDS subcuticular continued repairing. When urethroplasty surgery is made with PDS subcuticular continued repairing less complication ratios have been determined. We have applied 6/0 subcuticular continued repairing in our cases. None of our patients had complications.

Elbakry and Snodgrass showed in their studies that regular urethral dilatation after Snodgrass surgery can decrease the development of narrow meatus and occurence of fistulas 
(Elbakry, 1999; Snodgrass, 1999a). We checked our patients' urination calibrates postoperatively in the $2^{\text {nd }}, 4^{\text {th }}, 8^{\text {th }}$, and $16^{\text {th }}$ weeks and dilated the meatus with $6 \mathrm{f}$ and $8 \mathrm{f}$ urethral dilatator. As we have foreseen, none of our patients had narrow meatus.To minimize the edema and bleeding after hypospadias surgeries compressed coverings are suggested (Borer and Retik, 1999). We applied postoperative coban bandage and compressed dressing to our patients. None of our patients had bleeding or edema that needed medical intervention.

\section{Conclusion}

It is significant that the doctor involved in hypospadias surgery must be capable of applying various surgical techniques because of the anatomopathological characterics of this disorder. TIPU operation is an easy and practical technique that can be applied to all kinds of distal hypospadias cases. The necessity for reoperations is less in this method, when compared with others. TIPU is the most outstanding treatment alternative in distal hypospadias with its advantages such as less complication, perfect cosmetic and functional results. We also believe that less complication rates and reoperation necessity can even be decreased by using PDS suture in urethroplasty and silicon stent, and applying periodical urethral dilatation during the early postoperative period.

\section{REFERENCES}

Baskin, L.S., Ebbers, M.B., 2006. Hypospadias: Anatomy, etiology and technique. J. Pediatr. Surg. 41, 463-472.

Borer, J.G., Retik, A.B., 1999. Current trends in hypospadias repair. Urol Clin North Am. 26, 15-37.

Cooper, C.S., Synder, H.M., 2000. Pediatric reconstructive surgery. Curr Opin Urol. 10, 195-199.

Duckett, J.W., Synder, H.M., 1992. MAGPI hypospadias repair after 1000 cases avoidance of meatal stenosis and regression. J. Urol. 147, 665669.

Ebu-Arafeh, W., Chertin, B., Zilberman, M., 1998. One stage repair of hypospadias: Experience with 856 cases. Eur Urol. $34,365-367$.

Elbakry, A., 1999. Tubularized-incised urethral plate urethroplasty: Is regular dilatation necessary for success? BJU Int. 84, $683-688$.

Hadidi, A.T., Azmy, A.F., 2004. Hypospadias Surgery: An Illustrated Guide. Berlin Heidelberg: Springer-Verlag. 51-163.

Kayıkç1, A.M., Çam, K., Akman, R.Y., Erol, A., 2005. The ratio of external genital anomalies in male children attending primary school in Düzce. Turkish Journal Of Urology. 31, 79- 81.

Küçükaydın, M., Okur, H., Kazez, A., 1996. Meatal advancement and glanuloplasty (MAGPI) and modified MAGPI experience in 104 patients. Ped. Cer. Derg. 10, 9-12.

Oswald, J., Körner, I., Riccabona, M., 2000. Comparison of the perimeatal-based flap (Mathieu) and the tubularized incised-plate urethroplasty (Snodgrass) in primary distal hypospadias. BJU International. 85, 725-727.

Park, J.M., Faerber, G.J., Bloom, D.A., 1994. Longterm outcome evaluation of patients outgoing the MAGPI procedure. J Urol. 152, 12291231.

Snodgrass, W., J., 1994. Tubularized, incised plate urethroplasty for primary distal hypospadias. Urology. 151, 464-465.

Snodgrass, W., 1999a. Does tubularized incised plate hypospadias repair create neourethral strictures? J Urol. 162, 1159-1161.

Snodgrass, W., 1999b. Suture tracks after hypospadias repair. BJU Int. 84, 843-844.

Snodgrass, W.T., Shuka, A.R., Canning, D.A. 2007. Hypospadias in In The Kelalis-King-Belman. Docimo, S.G., Canning, D.A., Khoury, A.E. (eds). Textbook of Clinical Pediatric Urology. 5 th ed. Informa healtcare. 71, 1205-1235.

Söylet, Y., 2010. Penile abnormalities. Turk. Arch. Ped. 45 Suppl. 94-99.

Ulman, I., Erikçi. V., Avanoğlu, A., Gökdemir, A., 1997. The effect of suturing technique and qamaterial on complication rate following hypospadias repair. Eur. J. Pediatr. Surg. 3, 156-157.

Uygur, C., Unal, D., Tan, M.O., 2002. Factors affecting outcome of one stage anterior hypospadias repair: Analysis of 422 cases. Pediatr Surg Int. 18, 142-146.

Yesildag, E., Tekant, G., Sarımurat, N., Buyukunal, S.N.C., 2004. Do patch procedures prevent complications of the Mathieu technique? J. Urol. $171,2623-2625$. 